\title{
FORMAÇÃO DE PROFESSORES DE HISTÓRIA: INSTITUCIONALIZAÇÃO E PESQUISAS ACERCA DA FORMAÇÃO
}

\author{
TRAINING OF HISTORY TEACHERS: INSTITUTIONALIZATION AND SURVEYS \\ ABOUT TRAINING
}

Gionara Tauchen ${ }^{1}$

Júlia Silveira Matos²

Maria Caroline Aguiar da Silveira ${ }^{3}$

\begin{abstract}
RESUMO: No presente artigo buscamos compreender os processos de institucionalização da História enquanto um curso de Ensino Superior, atentando para a relação que a licenciatura estabeleceu em termos curriculares desde a gênese desse processo. Procurando ampliar as compreensões a respeito das temáticas relacionadas à formação de professores de história e do currículo, realizamos uma pesquisa bibliográfica, do tipo Estado da Arte (FERREIRA, 2002), utilizando a base de dados da SCiELO e o portal de periódicos da CAPES. Buscamos por descritores referentes à formação de professores/as de história, licenciatura em história, ensino de história relacionado aos aspectos formativos e institucionais, institucionalização dos cursos de história e currículo do curso de história. Identificamos 11 artigos, os quais balizados pela Análise de Conteúdo (BARDIN, 1977), nos possibilitaram construir um panorama sobre as principais preocupações temáticas pertinentes à formação de professores de história.
\end{abstract}

Palavras-chave: Formação de professores de História. Estado da arte. Currículo.

\begin{abstract}
In this article we seek to understand the processes of institutionalization of History as a course of Higher Education, taking into account the relationship that the degree has established in curricular terms since the genesis of this process. In order to broaden the understanding of the themes related to the formation of teachers of history and curriculum, we carried out a bibliographical research, such as State of the Art (FERREIRA, 2002), using SciELO and the CAPES journal portal. We search for descriptors referring to the formation of teachers of history, degree in history, teaching of history related to the formative and institutional aspects, institutionalization of history courses and curriculum of history course. We identified eleven articles, which were marked by Content Analysis (BARDIN, 1977), and allowed us to construct a panorama on the main thematic concerns related to the formation of teachers of history.
\end{abstract}

Keywords: History teacher training. State-of-the-art. Curriculum.

1 Prefeitura Rio Grande - FURG e Doutora em Educação.

2 Universidade Federal do Rio Grande - FURG e Doutora em História.

3 Prefeitura de Capão da Canoa - Professora de História e Mestre em Educação.

História \& Ensino, Londrina, v. 27, n. 1, p. 29-52, jan./jun. 2021 


\section{Introdução}

Nos cursos destinados à formação de professores de história, majoritariamente, as discussões relacionadas aos processos de ensino e aprendizagem localizam-se nas disciplinas intituladas prática de ensino, estágio supervisionado, metodologia do ensino, práticas pedagógicas; muitas delas sob a tutela dos departamentos ou institutos de Educação.

A formação para a licenciatura em História, no Brasil, se instituiu a partir dos cursos de bacharelado, sendo constituída em um ano extra de disciplinas de cunho didático e pedagógico. Seu caráter histórico expressa essa dualidade presente na gênese dos cursos de licenciatura, uma vez que as disciplinas pedagógicas eram oferecidas separadamente da formação específica em História. Além disso, conforme evidenciam algumas pesquisas (FERREIRA, 2012; NASCIMENTO, 2013; RODRIGUES, 2013; ROIZ, 2007; SILVA; FERREIRA, 2011), as próprias disciplinas da licenciatura são atribuídas a outros departamentos e institutos, responsáveis pelas disciplinas pedagógicas, dissociando-se, muitas vezes, as intencionalidades e os propósitos formativos.

Neste sentido, esta pesquisa busca compreender e evidenciar a estruturação e distinção curricular histórica, justamente pelo abismo sentido entre as disciplinas de formação específica para história e as disciplinas de formação pedagógica. Além disso, intentamos tecer apontamentos no que se refere à relação que se estabeleceu com a formação para licenciatura em História em termos curriculares.

\section{A institucionalização da História em curso superior}

Em locais como Europa e Estados Unidos, a institucionalização dos cursos de História surgiu na segunda metade do século XIX e século XX, extremamente relacionada à afirmação nacional, consolidação das elites e progresso cientifico e econômico (SILVA; FERREIRA, 2011, p. 284). No Brasil, as primeiras instituições de ensino superior eram de cunho religioso, sendo administradas principalmente por jesuítas. É com a chegada da família real, em 1808, que se inicia um processo de alteração do ensino superior, com o intuito de formar profissionais 
de modo a suprir as necessidades do aparelho estatal. Retira-se, portanto, o ensino superior das ordens de cunho religioso e as disciplinas passam a ser ofertadas nas academias militares e faculdades de Direito. Ao longo do século XIX, o Brasil contou com a criação e fechamento de inúmeras tentativas de Universidade em diversos estados. Foi apenas em 1920, no Rio de Janeiro, que se inaugura a primeira universidade do país.

Os primeiros cursos de História em instituições de ensino superior públicas ocorreram em 1934, na Universidade de São Paulo - USP e em 1935, pela Universidade do Distrito Federal - UDF. Cabe salientar que o período em que as institucionalizações dos cursos de História no Brasil, na década de 1930, marca uma nova forma de governo iniciada por Vargas, rompendo com os moldes tradicionais de poder oligárquico.

É a década de 1930, portanto, que marcará o início da História institucionalizada vinculada a um projeto de ensino superior. O modelo universitário das Faculdades de Filosofia sofre influência direta da intelectualidade francesa. Ferreira (2012) ressalta tanto a importação de professores quanto as narrativas teóricas e metodológicas francesas para os cursos de história no Brasil. Muito cara a essa perspectiva é a questão da história nacional, embasada na necessidade de se fortalecer um espírito de nação, sentimento de pertencimento e nacionalidade.

Segundo Silva e Ferreira (2011, p. 286-287)

[...] o novo governo preocupou-se com a formação de uma elite mais ampla e intelectualmente mais preparada. Assim, formatou um modelo de sistema educativo laico, partindo do centro para a periferia, ou seja, da capital do país para o interior.

As reformas educacionais que se seguiram, com a criação do Ministério da Educação e Saúde Pública e com a administração de Francisco Campos e Gustavo Capanema, buscavam estabelecer um sistema nacional de ensino, tanto básico quanto universitário. Parte desse período um projeto realmente regulamentado e regular de Ensino Superior no país, bem como a perspectiva de uma formação institucionalizada. 
Com a Reforma do Ensino de 1931, efetuada pelo então ministro Francisco de Campos, houve as primeiras tentativas de formação de pessoal qualificado para suprir as necessidades do ensino 'primário' e'secundário', e se discutia o aparecimento da figura do filósofo, geógrafo e historiador, profissional. Nesse sentido, a Universidade de São Paulo, criada em 1934, foi uma das pioneiras, neste projeto político, institucional e intelectual. Até a criação do curso de Geografia e História nas Faculdades de Filosofia na década de 1930, o exercício do ofício de historiador foi praticado, no Brasil, por aqueles que se dedicavam ao estudo do passado e escreviam textos que, reconhecidas suas especificidades, poderiam ser entendidos como de história. (ROIZ, 2007, p. 70)

Esses entendimentos de Roiz (2007) nos levam a questionar quem eram os sujeitos que desempenhavam o papel de historiadores no país. Quem foram os primeiros historiadores do Brasil? Homens formados nos campos disciplinares mais tradicionais e que, num sentido de "vocação", escreviam a respeito da história; mas uma perspectiva de história positivista, calcada em fatos, datas e personalidades (ROIZ, 2007), evidenciando a falta de formação específica para as humanidades.

Os profissionais eram formados na área de medicina, engenharia, direito. É na década de 30 do século XX que a formação de intelectuais e de professores passa a ser uma preocupação das políticas educacionais no Brasil.

No Manifesto dos Pioneiros da Educação Nova (1932) (AZEVDO et al., 2006), encontramos considerações pertinentes a respeito da formação de professores. Segundo o documento, a formação de professores calcada em aspectos metodológicos, teóricos e pedagógicos próprios de um profissional da educação não havia sido pensada até então. Segundo os relatores

[...] não recebe, por via de regra, nesses estabelecimentos, de nível secundário, nem uma sólida preparação pedagógica, nem a educação geral em que ela deve basear-se. A preparação dos professores, como se vê, é tratada entre nós, de maneira diferente, quando não é inteiramente descuidada, como se a função educacional, de todas as funções públicas a mais importante, fosse a única para cujo exercício não houvesse necessidade de qualquer preparação profissional (AZEVEDO et al., 2006, p. 200).

Conclui-se que um projeto de consolidação nacional em termos de Educação necessitaria de um centro próprio para formar professores de todas as áreas, não mais ligados as profissões liberais, entendidas nesse contexto como 
Engenharia, Medicina e Direito, mas uma formação sólida e ancorada nas especificidades teóricas e práticas de tal profissão.

Por isso, salientamos o caráter de formação atribuído às Faculdades de Filosofia, ou Institutos de Filosofia. A necessidade de formação de professores e professoras para o ensino secundário é um mobilizador desses cursos. Tanto que, posteriormente, a partir da década de 1940, serão incluídas no currículo as disciplinas de cunho pedagógico e didático. Aos Institutos ou Faculdades de Filosofia, Ciências e Letras ficou a tarefa da formação dos/as professores destinados ao ensino primário e secundário, procurando atender a essa nova demanda de profissionais especializados para a docência.

O próprio conceito de licenciatura era novo naquele momento, tendo em vista que eram homens formados nas profissões liberais que se tornavam professores. Foi com o advento das Faculdades de Filosofia, Ciências e Letras que a licenciatura enquanto ênfase de formação pedagógica começou a ser pensada e instaurada. Ainda segundo Roiz

[...] foi a partir da década de 1930 que, de um lado, o professor secundário formado pelas universidades passava a fazer parte do sistema escolar vigente, e de outro, começava a ser pensada a figura e o papel do filósofo, do cientista social e político, do geógrafo e do historiador, na sociedade (ROIZ, 2007, p. 78).

A USP e a Faculdade de Filosofia, Ciências e Letras, dentro das reformas educacionais encabeçadas por Capanema, desempenharam um papel primordial no que diz respeito aos cursos de História. Os objetivos principais da Universidade de São Paulo eram formar uma elite intelectual nacional, além da formação de professores para nível secundário e universitário. Em relação à função de formação de professores, Silva e Ferreira (2011, p. 290) apontam que a Faculdade de Filosofia, Ciências e Letras ficou responsável "pelos cursos de licenciatura em Filosofia, Ciências Matemáticas, Ciências Físicas, Ciências Sociais e Políticas, Letras Clássicas e Português e Geografia e História, que deveriam ser organizadas segundo as diretrizes nacionais". Ainda segundo as autoras, o curso de Geografia e História ficaria incumbido da formação dos professores de todos os níveis e da história do país e de aspectos até então pouco conhecidos, sendo estruturado em três anos de duração. 
Acerca da estrutura curricular do curso, em 1939, com o Decreto Lei no 1.190, de 4 de abril, ocorre uma reestruturação que atribui mudanças significativas aos cursos de História, que vão desde alterações curriculares e de duração do curso até desmembramento de disciplinas.

Com a criação da FNFi da UB, a UDF foi extinta em 4 de abril de 1939, e parte de seus quadros foi integrada à recém-criada faculdade. Uma nova fase no processo de institucionalização do ensino superior de história teve início então. E o novo modelo de graduação que se conformou nos anos seguintes tornou-se uma forte influência em todo o país (FERREIRA, 2012, p. 614).

Tal decreto ajustava o funcionamento de todas as faculdades de filosofia em um mesmo padrão organizacional, sendo a Universidade do Brasil, e a Faculdade Nacional de Filosofia, as instituições incumbidas de regulamentar a Educação Superior no Brasil.

A partir da reestruturação, o curso de História da USP transformou a cadeira de Geografia em duas novas cadeiras (Geografia Física e Geografia Humana) e a cadeira de História das Civilizações nas cadeiras de História da Civilização Antiga e Medieval e História da Civilização Moderna e Contemporânea. "Em 1942, também para se adaptar às determinações do Decreto 1.190, foi incluído o Curso de Didática, no qual passariam a ser ministradas as disciplinas de formação pedagógica". (SILVA; FERREIRA, 2011, p. 291)

A duração do curso também se altera, passando de três para quatro anos de duração, sendo este último totalmente dedicado às disciplinas de caráter pedagógico, sendo estas, didática geral, didática especial, psicologia educacional, administração escolar e educação comparada, fundamentos biológicos da educação, fundamentos sociológicos da educação. Assim, aqueles que concluíssem as disciplinas dos três anos obtinham o diploma de bacharel, necessário para quem desejasse ingressar no último ano e receber o diploma de licenciado.

Em 1955 ocorre a divisão dos cursos de História e Geografia, estruturando-se em um currículo ainda muito similar ao que possuímos hoje, com duração de quatro anos e ainda dependendo da formação em Didática e Psicologia para a obtenção do diploma de licenciado. 
O modelo de História presente em ambos os currículos valorizava a história nacional, por meio da ênfase aos grandes heróis nacionais. A formação para a licenciatura, até fins da década de 1930, compreendia a formação específica em qualquer curso, sendo o exercício do magistério destinado àqueles que concluíssem as disciplinas de cunho pedagógico, que poderiam ser cursadas concomitantemente ao terceiro ano do curso específico.

Porém, com os decretos nacional 1.190 de 1939 e estadual 12.511 de 1942, que estabeleceram o funcionamento e a nova estrutura curricular das Faculdades de Filosofia, Ciências e Letras do Estado de São Paulo, o currículo passou a ter quatro anos, sendo o último ano destinado às disciplinas de formação pedagógica para a obtenção do título de licenciado/a em História. Possui, portanto, um caráter histórico, uma vez que na fundação da licenciatura em história, estas disciplinas já eram oferecidas separadamente da formação específica em História.

Um aspecto sempre ressaltado quando se trata da contextualização e historicização da História no Brasil é o período da Ditadura Civil-Militar e as políticas educacionais que daí surgiram. Foi uma série de medidas que causaram enorme retrocesso em relação ao ensino de História e a própria produção do conhecimento histórico, além da desestruturação e sucateamento da formação de professores e professoras na área de ciências humanas. A aproximação entre a Educação Básica e a Superior foi retomada apenas a partir da década de 1980, com o fim da Ditadura Civil-Militar e o início do processo de redemocratização do país.

Fonseca (2011) aborda as condições nas quais se encontrava a educação brasileira na década de 90, como consequência das medidas autoritárias e liberais adotadas na Ditadura Civil-Militar. Segundo a autora, "o papel da educação assim como as metas para o setor, estabelecidas pelo Estado brasileiro a partir de 1964, estiveram estritamente vinculadas ao ideário de segurança nacional e de desenvolvimento econômico" (FONSECA, 2011, p. 19). Percebemos, portanto, que esse período da história do Brasil significou um grande retrocesso em aspectos relacionados à educação pública, de qualidade e universal; mas, além disso, significou que ideias contraditórias ao ideal de segurança nacional não deveriam ser incentivadas, ocasionando uma quase 
extinção das ciências humanas nos currículos. A partir de tais medidas, o que ocorre na educação brasileira, a partir do golpe de 1964, foi uma série de determinações que visam à repressão, à exclusão de camadas pobres ao acesso a educação superior, à privatização tanto da educação básica quando superior e a desestruturação do magistério.

A questão da universidade e da desestabilização do magistério são dois aspectos de extrema relevância, uma vez que compreendemos que os efeitos ocasionados pela intensa repressão e desestruturação da educação brasileira são sentidos ainda hoje na forma como a Licenciatura segue sendo tratada dentro das Universidades. Com a reforma do ensino superior em 1968, a universidade também acabou por se adequar ao ideário que permeou as iniciativas adotadas pelo Estado brasileiro, sendo subordinada ao controle e vigilância do governo militar.

Acreditamos ser de extrema pertinência trazer esses apontamentos referentes à educação, à universidade e à História dentro desse período que perdurou por 21 anos, pois as mudanças radicais e drásticas, que ocasionaram em inúmeros retrocessos, causaram danos que permanecem. Um exemplo disso são as licenciaturas curtas, que atacavam diretamente a formação profissional de professores e professoras, submetendo-os à lógica capitalista da mercantilização da educação. Sobre isso, Fonseca destaca que "o papel dos cursos de licenciatura curta atendia à lógica deste mercado: habilitar um grande número de professores da forma mais viável economicamente: cursos rápidos e baratos exigindo poucos investimentos para sua manutenção" (FONSECA, 2011, p. 27). Fica evidente, a partir das colocações da autora, que quanto menos qualificada fosse a formação dos/as profissionais da educação, mais conveniente era para o governo militar e a lógica liberal. Ainda sobre o papel que as licenciaturas curtas cumpriam em relação aos planos do governo, a autora evidencia que

[...] o profissional oriundo da licenciatura curta estava mais propenso a atender aos objetivos do Estado, aos ideais de segurança nacional [...] A licenciatura curta generalizante, não preparando suficientemente o professor para o trabalho nas escolas, acabava, na maioria das vezes, empurrando-o para a alternativa mais cômoda, ou seja, utilizar o manual didático, reproduzindo-o de forma quase absoluta, reforçando um processo de ensino em que não há espaço para a crítica e a criatividade (FONSECA, 2011, p. 29). 
Dessa forma, mantém-se a lógica dominante e o controle social, aparando qualquer senso crítico e de autonomia que poderia surgir nos meios escolares, através do trabalho dos professores.

Ainda nesse caminho, mais uma série de medidas são tomadas de modo a desvalorizar cada vez a formação de professores de humanidades, incluindo aqui a formação de professores e professoras de História. Quando se converte uma série de disciplinas da área de ciências humanas em uma grande área denominada Estudos Sociais, é tirado do professor de História a competência para lecionar tanto a disciplina História quanto a nova disciplina de Estudos Sociais. A partir desse fato, se iniciam as implementações das licenciaturas curtas e longas em Estudos Sociais. Condiciona-se, dessa forma, uma formação ampla, generalizante e que não contribui para uma formação cientifica, crítica e autônoma, ocasionando na formação de uma

[...] nova geração de professores polivalentes, e neles o principal objetivo é a descaracterização das ciências humanas como campo de saberes autônomos, pois são transfiguradas e transmitidas como mosaico de conhecimentos gerais e superficiais da realidade social (FONSECA, 2011, p. 28).

As análises de Fonseca acerca das políticas educacionais adotadas pelo governo militar nos auxiliam na tarefa de elucidar o caráter ideológico de controle social que permearam as medidas que foram acima citadas. Investir contra os/as professores/as com legislações que visavam sucatear e desestruturar a formação de tais profissionais demonstra a preocupação por parte do governo em manter a hegemonia e conquistar legitimidade, retirando do âmbito educacional qualquer instrumento de crítica.

É apenas no final de década de 70 e início da década de 80 que, a partir de demandas e lutas sociais por parte de universidades, professores, entre outros setores, que gradualmente se iniciam as mudanças referentes ao ensino de História e a forma como havia sido configurado até então.

Julgamos ser necessário trazer essas discussões em nossa pesquisa por compreendermos que as medidas adotadas ao longo do período no qual vigorou o sistema político da Ditadura Civil-Militar e suas políticas de retrocesso e 
controle social deixaram cicatrizes referentes ao ensino de História e a formação de professores e professoras de História. Durante o período, o ensino de História se configurou enquanto um meio de manter a hegemonia e legitimidade do governo, além do controle da memória coletiva por meio de conteúdos muito pouco significativos, calcados em fatos e datas, objetivando a formação de uma moral nacional. Infelizmente, o ensino de História ainda carrega algumas marcas desse período, sendo visto e mesmo tratado enquanto uma disciplina ligada a memorização de fatos distantes, que muito pouco instiga aos alunos.

Compreendemos que a estrutura curricular modela a forma como as disciplinas da licenciatura são organizadas ainda hoje. Consideramos pertinente salientar as relações licenciatura e bacharelado, uma vez que a separação definitiva, em 2001, dos cursos de História licenciatura e História bacharelado visou não mais sobrepor a formação específica sobre a formação pedagógica, e para tal separaram-se os cursos de modo a criar uma identidade na formação de professores. Entretanto, os currículos de formação expressam, muitas vezes, que a única diferenciação entre os cursos consiste nas disciplinas destinadas a formação pedagógica e docente para aqueles que ingressam em História licenciatura

\section{Procedimentos metodológicos}

O estudo foi organizado por meio de pesquisa tipo Estado da Arte, na qual, nos bancos de dados da SCIELO e periódicos da CAPES buscamos por descritores referentes à formação de professores/as de história, licenciatura em história, ensino de história relacionado aos aspectos formativos e institucionais, institucionalização dos cursos de história e currículo do curso de história.

Segundo Ferreira (2002, p. 257), pesquisas do tipo Estado da Arte são também chamadas de pesquisas acerca do "estado do conhecimento" e procuram trazer a tona o que vem sendo produzido academicamente em termos de espaço e tempo sobre determinadas temáticas. É, portanto, uma pesquisa de caráter bibliográfico. Ainda segundo a autora, o que motiva esse tipo de pesquisa é o sentimento de não conhecermos as pesquisas realizadas no Brasil, que vem observando um crescimento bastante acelerado em suas produções acadêmicas. 
Essa modalidade de pesquisa nos auxilia na construção de nossas próprias hipóteses, referências e domínio a respeito da temática que procuramos desenvolver nesse trabalho.

Conforme a tabela abaixo, localizamos onze artigos, os quais foram organizados de acordo com as duas categorias emergentes da Análise de Conteúdo: currículo, articulação dos saberes (quadro 1) e história do currículo/formação (quadro 2).

Quadro 1 - Currículo, articulação dos saberes

\begin{tabular}{|l|l|}
\hline \multicolumn{1}{|c|}{ Currículo e articulação entre os saberes } & CD \\
\hline PACIEVITCH, C. Conhecimento didático e formação de professores de & CAS01 \\
história: contribuições para a teoria e a prática. Diálogo Andino, & \\
n. 52, p. 117-126, 2017. & \\
\hline MESQUITA, I. M.; FONSECA, S. G. Formação de professores de & CAS02 \\
História: experiências, olhares e possibilidades. História Unisinos, v. & \\
10, n. 3, p. 333-343, set./dez. 2006. & \\
\hline $\begin{array}{l}\text { RICCI, C. S. Historiador e/ou professor de História: a formação nos } \\
\text { cursos de graduação de História. Revista História Hoje, v. 4, n 7, p. }\end{array}$ & \\
107-135, 2015. & \\
\hline $\begin{array}{l}\text { NASCIMENTO, A. P. Mil horas para quê? A prática como componente } \\
\text { curricular na Licenciatura em História. Antíteses, v. 6, n. 12, p. 35- }\end{array}$ & \\
52, jul./dez. 2013. & \\
\hline $\begin{array}{l}\text { SOARES, O. P. Os currículos para o ensino de história: entre a CAS05 } \\
\text { formação, o prescrito e o praticado. Antíteses, v. 5, n. 10, p. 613- } \\
\text { 634. Jul./dez. 2012. }\end{array}$ & \\
\hline
\end{tabular}

Fonte: As autoras.

Quadro 2 - História do currículo/formação

\begin{tabular}{|l|l|}
\hline \multicolumn{1}{|c|}{ Formação de professores de história } & CD \\
\hline NASCIMENTO, T. R. A formação do professor de História no Brasil: & FPH01 \\
percurso histórico e periodização. Revista História Hoje, v. 2, n. 4, p. & \\
265-304, 2013. & \\
\hline
\end{tabular}




\begin{tabular}{|c|c|}
\hline $\begin{array}{l}\text { FERREIRA, M. M. O ensino da história na Faculdade Nacional de } \\
\text { Filosofia da Universidade do Brasil. História, ciências, saúde- } \\
\text { Manguinhos, Rio de Janeiro. V. 19, n.2, abr./jun. } 2012 \text {. }\end{array}$ & 12 \\
\hline $\begin{array}{l}\text { SCHMIDT, M. A. História do ensino de história no Brasil: uma } \\
\text { proposta de periodização. Revista História da Educação - RHE. V. 16, } \\
\text { n. } 37 \text {, p. } 73-91 \text {, maio/ago. } 2012 \text {. }\end{array}$ & $\mathrm{FPHO3}$ \\
\hline $\begin{array}{l}\text { FREITAS, I. Reformas educacionais e os currículos nacionais para o } \\
\text { ensino de história no Brasil republicano (1931/2009). Cadernos de } \\
\text { História da Educação, v. } 12 \text {, n. 1, p. } 187-202 \text {, jan./jun. } 2013 \text {. }\end{array}$ & FPHO4 \\
\hline $\begin{array}{l}\text { ROIZ, D. S. A institucionalização do ensino universitário de Geografia } \\
\text { e História na faculdade de filosofia, Ciências e Letras da Universidade } \\
\text { de São Paulo entre } 1934 \text { e } 1956 \text {. Agora, v. } 13 \text {, n. 1, p. 65-104, } \\
\text { jan./jun. } 2007 \text {. }\end{array}$ & FPH05 \\
\hline $\begin{array}{l}\text { RODRIGUES, M. C. M. A formação superior em história na } \\
\text { UPA/URGS/UFRGS de 1943-1971. História da Historiografia, n. 11, p. } \\
\text { 122-139, abr. } 2013 .\end{array}$ & FPH06 \\
\hline
\end{tabular}

Fonte: As autoras.

Para análise dos dados, utilizamos a Análise de Conteúdo (BARDIN, 1977). Segundo a autora, o método da análise de conteúdo divide-se em três momentos principais: 1- pré-análise, a fase de organização na qual selecionamos os documentos que serão analisados a partir de hipóteses estabelecidas a priori, segundo nossos objetivos; 2- a exploração do material, na qual a partir da leitura e fichamento dos artigos selecionados, pudemos elencar nossas categorias; 3- o tratamento dos resultados, inferência e interpretação, na qual estabelecemos resultados considerados significativos para a análise que nos propomos a fazer. $\mathrm{Na}$ figura abaixo expressamos os núcleos temáticos dos estudos analisados, decorrente da compilação das palavras-chave informadas nos artigos. A imagem foi produzida pelo aplicativo Word Cloud Generator.

Figura 1 - Compilação de palavras-chave dos artigos 


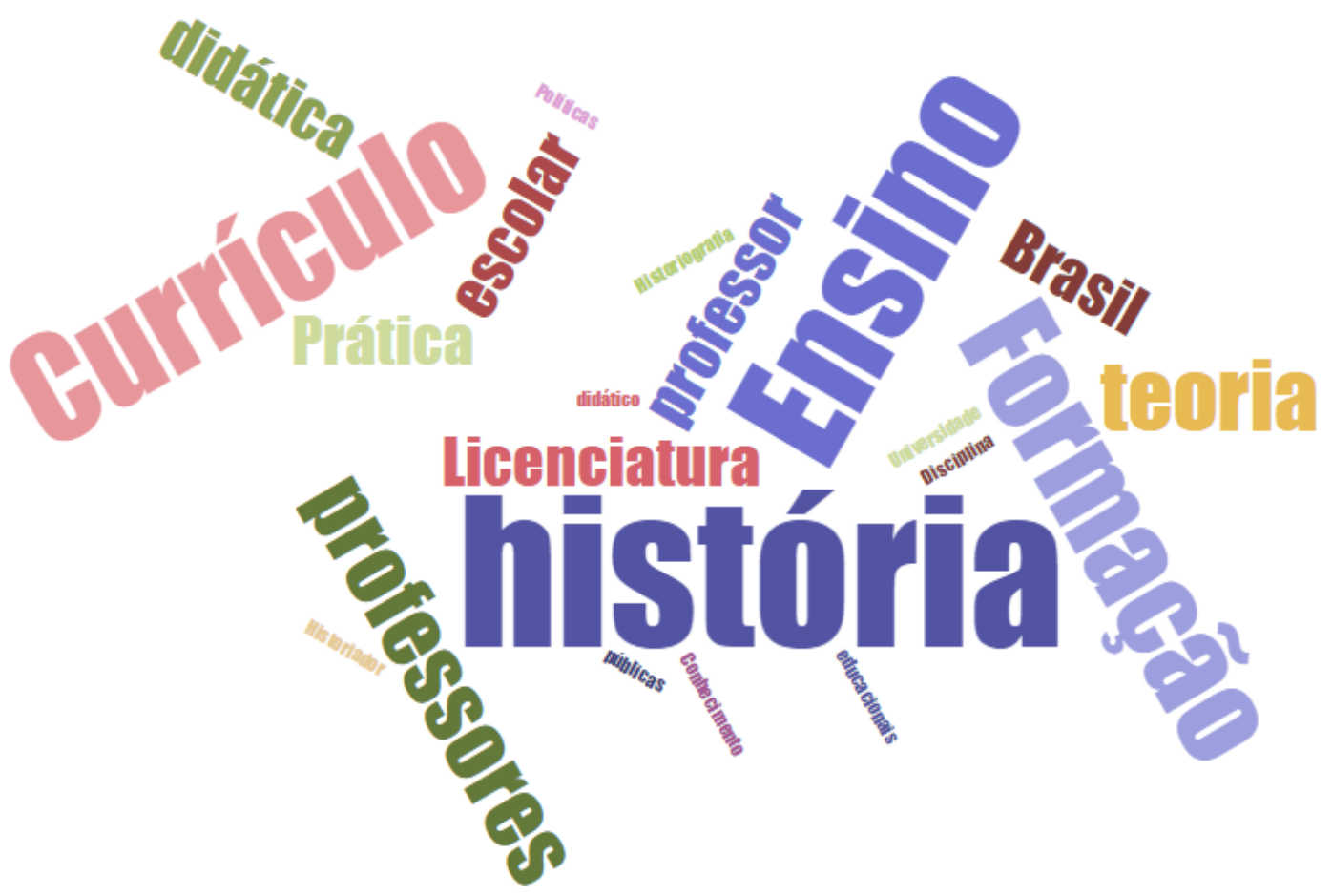

Fonte: As autoras.

A partir desse levantamento, produzimos o metatexto referente às duas categorias emergentes: currículo, articulação entre saberes, formação de professores de história.

\section{Formação de professores de história}

Três trabalhos abordam as questões referentes à constituição e configuração dos cursos de História nas primeiras universidades federais do Brasil, sendo estes Ferreira (2012), Roiz (2007) e Rodrigues (2013). Nascimento (2013), também aborda a questão dos primeiros cursos, e realiza uma periodização da formação de professores de História, abordando questões legais e curriculares centradas nesse aspecto.

Sua pesquisa evidencia pouca atenção em relação à história da formação e destaca que um dos temas centrais apontados a respeito da formação de professores de História diz respeito, entre outros pontos, à dicotomia licenciatura/bacharelado e teoria/prática na configuração curricular dos cursos de História. Aponta a historicidade de algumas questões que são centrais e 
recorrentes em relação às demandas formativas apontadas em muitas pesquisas a respeito dos currículos, como é caso da relação teoria e prática.

A formação pedagógica, dentro dos primeiros cursos, ficava a cargo das faculdades de educação, como já foi salientado na pesquisa. Segundo o autor,

Os primeiros cursos dessa instituição se constituíram no chamado modelo ' $3+1$ ', isto é, três anos de formação específica (bacharelado) somados a um ano de licenciatura ou formação pedagógica. Após cursarem as disciplinas específicas do curso de História e Geografia, os discentes se dirigiam ao Instituto de Educação a fim de cursarem as disciplinas pedagógicas (NASCIMENTO, 2013, p. 269).

Destacamos a característica curricular da licenciatura como sendo relegada a um ano extra de disciplinas de caráter didático complementando a formação do bacharelado. O licenciado, portanto, era aquele que concluía o curso de Didática. (NASCIMENTO, 2013, p. 269).

Ferreira (2012), Roiz (2007) e Rodrigues (2013) não enfocam questões referentes especificamente à formação de professores de História, porém, suas análises curriculares e legais nos permitiram tecer algumas hipóteses e considerações a respeito dessa formação. As pesquisas salientam que era um curso bastante abrangente em termos curriculares, que buscava produzir noções de história mundial e nacional, além de aspectos geográficos e linguísticos da formação do Brasil, estando bastante atrelado às questões de formação nacional, bem como às correntes e debates historiográficos que surgiam na Europa principalmente.

Na Faculdade Nacional de Filosofia da Universidade do Brasil, constituída para ser o padrão regulador das demais, História e Geografia estavam articuladas em um único curso e a formação dava-se, principalmente, para suprir a necessidade de professores para nível secundário. Segundo Ferreira (2012, p. 616), "[...] forjou-se um modelo de curso universitário de história que privilegiava a formação de profissionais do ensino secundário desvinculada da pesquisa histórica." Portanto, mais uma vez fica evidenciado o caráter histórico da desvinculação entre os aspectos formativos do profissional da História, compreendendo que essa formação não se dá apenas pelo saber pedagógico ou do conhecimento, mas de uma relação entre ambos. 
Roiz (2007) e Rodrigues (2013) também abordam a falta de investimentos e a iniciativa particular de alguns professores em desenvolver a pesquisa histórica dentro dos cursos de História. Porém, não há qualquer menção ao fato da pesquisa estar ligada à docência, ou seja, a formação continuava sendo pensada como aspecto a parte. Algumas medidas legais foram adotadas para tentar melhorar a qualidade da formação dos professores, como é o caso dos Ginásios de Aplicação, espécie de "estágio supervisionado", porém sua implementação não obteve grande sucesso.

As contribuições de Roiz (2007) centram-se em ressaltar questões de estrutura curricular e evidenciar a história recente da formação para a licenciatura no Brasil. Conforme aponta, foi apenas a partir da década de 1930 que esse profissional formado para dar aulas passou a existir institucionalmente. Segundo o autor

[...] determinava que o bacharel que concluísse o 'Curso de didática' é que seria conferido o 'diploma de licenciado no grupo de disciplinas que formarem o seu curso de bacharelado' (art. 49). Separa[va]-se, pois, o diploma de bacharel e o de licenciado, embora o segundo supusesse o primeiro (ROIZ, 2007, p. 82).

Compreendemos que esse fato demonstra a separação curricular e formativa dos saberes do conhecimento e dos saberes pedagógicos. Compreendia-se a formação pedagógica como técnicas e teorias provenientes de diversos campos, tais como a Didática, a Psicologia, sem que, no entanto, ocorresse um diálogo dessas áreas com a ciência específica que seria trabalhada pelo professor.

Rodrigues (2013), ao analisar o curso da atual Universidade Federal do Rio Grande do Sul, destaca os mesmos aspectos de estruturação curricular, levando em consideração que a Faculdade Nacional de Filosofia padronizava todos os currículos. Porém, a autora destaca que, mesmo com as reformas posteriores a extinção das Faculdades Nacionais de Filosofia "a segmentação entre a formação oferecida pelas disciplinas do departamento de história e a formação didática e pedagógica só fez aumentar [...]" (RODRIGUES, 2013, p. 135).

Nascimento (2013) retoma as dificuldades de se articularem os dois aspectos da formação de um professor de história, ressaltando o quanto é 
debatida e apontada o distanciamento curricular e prático dos saberes pedagógicos para com os saberes do conhecimento, dificultando a formação de um profissional capaz de articular de maneira efetiva dois aspectos indissociáveis de sua formação:

Os cursos de formação de professores, muito além de formarem pessoas capacitadas a ministrar determinados conteúdos, devem ser capazes de formar professores que produzam conhecimento, reflitam sobre suas práticas e pesquisem (NASCIMENTO, 2013, p. 295).

A formação do professor é reduzida à ideia de que boas técnicas de ensino garantam a aprendizagem.

Dentre as reformas curriculares e considerações apresentadas nos trabalhos analisados, nos interessa o fato que de a formação pedagógica continuava sendo concebida enquanto um aspecto adicional da estruturação curricular do bacharelado. As disciplinas do conhecimento tornavam-se mais sólidas e reformuladas para uma formação mais completa e eficiente em termos da ciência histórica, acompanhando intensamente os debates historiográficos, teóricos e metodológicos que vinham surgindo.

A formação pedagógica, porém, ainda estava a parte desse debate e seguia sendo concebida enquanto o ano extra de disciplinas de caráter didático e pedagógico, vinculadas aos departamentos ou faculdades de Educação. Além disso, mantinha-se a perspectiva de que as disciplinas pedagógicas consistiam em técnicas de ensino, portanto, se o professor tivesse um conhecimento sólido na sua área e boas técnicas, seria capaz de ensinar.

Nesse sentido, os trabalhos de Schmidt (2012) e Freitas (2013) ao abordarem questões referentes ao ensino de História e reformas educacionais respectivamente, nos permitem pensar a respeito da formação pedagógica dos professores de História e do processo de "pedagogização" dessa formação.

Segundo Schmidt (2012, p. 79),

Observa-se que, gradualmente e a partir de um diálogo com outras ciências, como a psicologia e a sociologia, foi ocorrendo a chamada pedagogização da História. Essa pedagogização caracterizou-se, principalmente, pela incorporação de aspectos relacionados aos métodos e técnicas de ensino e aos estudos 
referentes à personalidade e psicologia do educando, importados da Psicologia e da Didática Geral, indicando a existência de um novo tipo de conhecimento ou de uma didática específica, cujos conteúdos destinavam-se ao ensino e aprendizagem da história.

As considerações de Schmidt (2012), a respeito da pedagogização da História relacionada às disciplinas de caráter didático e pedagógico proposto nos currículos dos cursos destinados a formação de professores de História, evidenciam as dificuldades formativas no sentido de articulação entre os saberes, pois a formação específica estava desvinculada das discussões referentes ao ensino da ciência a que se destina a formação e abordagem dos conhecimentos pedagógicos seguira uma orientação mais positivista e tecnicista. Considera que "essa perspectiva ainda predomina, ainda que de forma diferenciada, em propostas de ensino de História no Brasil" (SCHMIDT, 2012, p. 80). Consideramos que essas colocações da autora dialogam com a estruturação curricular das disciplinas destinadas à formação pedagógica dos primeiros cursos de licenciatura em História. Evidenciam que as discussões referentes à aprendizagem histórica e seu ensino não estavam dentro dos debates propostos por historiadores.

Freitas (2013) discorre a respeito da necessidade da "fundação de uma Faculdade de Educação para 'pedagogizar' os docentes do curso secundário nacional [...]." (FREITAS, 2013, p. 189). Relaciona-se, assim, com a perspectiva abordada por Schmidt (2012) no que diz respeito à pedagogização do ensino de História, vista enquanto métodos e técnicas eficientes de ensino. Portanto, a necessidade de formação de professores estava atrelada a essa ideia de didática e pedagogia como os instrumentos necessários à docência.

Ainda segundo o autor,

Como vemos, pensar os currículos de história hoje - sobretudo no interior dos departamentos de história - é uma questão teórica e política muito importante e que não deve ficar relegada a um tópico de discussão de uma disciplina 'didática,' ministrada nos últimos períodos da licenciatura. Pensar currículos de história, sem nenhum exagero, é cultivar a manutenção da própria profissão que se quer ver reconhecida legalmente (FREITAS, 2013, p. 199).

Concluímos que repensar a formação inicial de professore(a)s de História em sua totalidade requer que ambos os campos disciplinares responsáveis por essa 
formação, ou seja, tanto a área do conhecimento específica e, portanto, seus docentes quanto a área da educação dialoguem em termos curriculares, mas também em termos departamentais e profissionais. Acreditamos que assim, possivelmente, estaremos trilhando um caminho para sair das críticas vazias e realmente realizarmos as mudanças almejadas para uma formação crítica, completa e fundamentada nos saberes necessários à formação dos nossos profissionais da educação.

\section{Currículo e articulação dos saberes}

Pacievitch (2017) discute a relação teoria e prática na formação de professores de história. Defende a ideia da articulação entre os saberes para uma formação intelectual ancorada na relação indissociável entre teoria e prática. Nascimento (2013) aborda a implementação de mil horas extras de atividades de prática de ensino nos cursos de licenciatura em História, numa tentativa de sanar o desequilíbrio entre teoria e prática. Ambos atentam para a relação deficitária entre as disciplinas, decorrentes das dificuldades de diálogo entre os saberes do conhecimento e os saberes pedagógicos e procuram problematizar a configuração curricular dos cursos de História, nos quais as disciplinas do conhecimento estão organizadas de forma a não serem contempladas com as discussões referentes ao ensino de tais conhecimentos.

A relação teoria e prática é um assunto recorrente dentro das pesquisas relacionadas à formação de professores de História, bem como a ausência de articulação entre os saberes pedagógicos e do conhecimento. Evidenciam o distanciamento curricular e departamental das disciplinas pedagógicas daquelas referentes ao conhecimento específico. Segundo Pacievitch

[...] bem como o alvo mais frequente de críticas sobre o curso de licenciatura, em que há forte separação entre as disciplinas pedagógicas e as historiográficas, sendo que a Didática da História (DH) brilha pela ausência. Em alguns casos, a separação é maior porque as disciplinas ligadas à prática de ensino são ministradas física e burocraticamente separadas do departamento de História. A relação entre teoria e prática é um problema tão frequente que é difícil encontrar artigos sobre formação de professores de história que não se refiram a ele (PACIEVITCH, 2017, p. 118). 
Nesse sentido, Nascimento indaga a respeito do papel dos professores universitários na articulação dos saberes, para além do que é proposto na organização curricular do curso.

Os currículos de graduação em História procuram integrar disciplinas obrigatórias (Brasil, América, África, Antiga, Medieval, Moderna e Contemporânea) com as ditas optativas (disciplinas com temas específicos), facilitando o contato do graduando com diferentes olhares sobre uma mesma temática, sem perder de vista os debates historiográficos existentes e a fundamentação teórico-metodológica que nos difere de outras disciplinas. O problema, então, reside na forma como nós professores poderemos trabalhar esse conteúdo teórico com a prática de ensinar História num espaço diferente e tão diverso como a escola (NASCIMENTO, 2013, p. 11).

Soares também problematiza a formação inicial, mas evidencia a interferência que a mesma tem em relação à forma como os licenciandos irão apreender o currículo escolar e suas práticas. Compreende que os licenciandos apreendem o currículo de sua formação com duas especificidades: um currículo que forma professores de História e outro que forma historiadores, levando em consideração a perspectiva que os próprios estudantes constroem sobre as disciplinas do conhecimento, que os auxiliaram nas suas concepções de História e as disciplinas pedagógicas, tidas como descontextualizadas da realidade escolar.

Embora haja necessidade de aprofundamento da análise, temos duas hipóteses iniciais: para os pibidianos, ainda há, mesmo que de forma subliminar, uma diferenciação entre formação do historiador e do professor de história; a estrutura curricular induz a este tipo de interpretação por parte dos licenciando, na medida em que impõe àqueles docentes da universidade que pesquisam em educação apenas a intervenção e leitura da realidade, ou seja, como se esses pesquisadores não se utilizassem da teoria (SOARES, 2013, p. 631).

Em relação às políticas educacionais e estruturação curricular, Mesquita e Fonseca (2006) investigam a formação do professor de História em diálogo com a formação inicial e a contribuição dos professores formadores para a efetivação das futuras práticas. O artigo analisa a formação nas décadas de 1980 e 1990 em três cursos de História em instituições de ensino superior de Minas Gerais, 
principalmente no que diz respeito às reformas estruturais e curriculares da História acadêmica e escolar que sucederam ao fim da Ditadura Civil-Militar. Ricci (2015), também aborda questões curriculares em diálogo com as políticas educacionais dos Parâmetros Curriculares Nacionais, das Diretrizes Curriculares Nacionais e o perfil desenhado pelas mesmas da profissão do historiador e do professor de história e suas implicações na estrutura curricular acadêmica. Atenta-se, principalmente, para a desarticulação entre os saberes do conhecimento e os saberes pedagógicos, provenientes da relação deficitária entre bacharelado e licenciatura.

Essa desarticulação encontra-se no perfil traçado em termos de competências e habilidade para o historiador e para o professor de história, relacionada à separação pesquisa e licenciatura ensino, compreendidas em termos de formação e política enquanto bacharel e licenciado, respectivamente e a falta de políticas efetivas que priorizassem a formação de professores de história até a década de 1990, com a LBD.

\begin{abstract}
A formação do professor de História, até esse período, não era um tema pautado pelos departamentos de História, na medida em que essa formação se resumia a frequentar as disciplinas pedagógicas oferecidas na Faculdade de Educação, especialmente em universidades públicas (RICCI, 2015, p. 128).
\end{abstract}

Articulam-se, portanto, reflexões a respeito das políticas educacionais decorrentes dos anos 1980 e 1990 em relação aos cursos de História. Exigia-se uma perspectiva diferente do que é um profissional da História, formado para trabalhar em diversas frentes, porém, os problemas relativos à desarticulação da formação de professores com os conteúdos ainda não foram resolvidos. Segundo Mesquita e Fonseca (2006), as alterações curriculares e legais em relação à reestruturação dos cursos de História reforçou "a separação ensino/pesquisa, bacharelado/licenciatura, o currículo passou a ser marcado por essa visão dicotômica, em que a teoria estava separada da prática, pelo menos no que dizia respeito à formação do professor" (MESQUITA; FONSECA, 2006, p. 336). Aponta, sobre a formação de professores de História, pouca relevância pré e pósreformulações, tendo em vista que o interesse era na dimensão da pesquisa e da 
pós-graduação, e, como se compreende a pesquisa vinculada estritamente ao bacharelado, esse foi o foco das mudanças.

A partir do que foi analisado nas pesquisas do Estado da Arte, a relação teoria e prática é bastante apontada como um dos principais problemas curriculares e metodológicos nos cursos de licenciatura em História. A concepção tradicional que se tem em relação à teoria e à prática aborda esses conceitos como autônomos, desarticulados e imutáveis. Entretanto, conforme Pimenta e Lima (2008), não é possível pensar em teoria ou prática, mas sim teoria e prática. Rays (1996) salienta ainda que precisamos superar a visão de conhecer para depois fazer, ou fazer e depois conhecer, mas pensar teoria e prática enquanto dinâmicas e complementares. Isolar esses componentes presentes na formação, bem como na atuação, de professore(a)s é simplificar e tornar muito abstratas as compreensões de mundo, de sujeito e dos saberes que estão constantemente sendo construídos no percurso formativo do(a)s aluno(a)sprofessores.

Ainda segundo Pimenta e Lima (2008, p. 44), dentro de um curso de formação de professores, é tarefa de todas as disciplinas habilitarem seus alunos para o exercício da sua profissão, fundamentado-os "a partir da análise, da crítica e da proposição de novas maneiras de fazer educação", portanto, não é tarefa apenas das disciplinas vinculadas a licenciatura, aquelas denominadas "práticas de ensino", mas de todo o currículo do curso evidenciar e proporcionar os conhecimentos necessários para esse processo.

\section{Considerações Finais}

Os trabalhos que tratam especificamente do currículo no ensino superior auxiliaram na compreensão do caráter histórico e institucional da divisão e supremacia do bacharelado sobre a formação para a licenciatura, bem como a falta de interação entre esses dois aspectos da formação dos profissionais da História. Podemos pensar que mesmo que o intuito dos cursos das Faculdades de Filosofia fossem suprir as demandas de formação de professores, isso não garantiu uma atenção especial a esse aspecto nos currículos e demandas 
internas das universidades; até mesmo porque a licenciatura foi instituída mais tarde dentro dos cursos de História.

As pesquisas que não abordam especificamente o currículo em nível de ensino superior auxiliaram, a partir de suas proposições a respeito do ensino de história e das reformas curriculares para a Educação Básica, a levantar algumas hipóteses e argumentos a respeito da formação de professores de história, da perspectiva que se traçou para o ensino de história no Brasil e como as questões metodológicas e pedagógicas interferiram na configuração da licenciatura em história no país.

A partir de tais colocações, nos dispomos a pensar a respeito de algumas demandas e anseios formativos sentidos por discentes e docentes. As pesquisas elencadas no eixo temporal atualidade do currículo e da formação evidenciaram pontos em comum sobre as principais problemáticas referentes à formação de professores de História.

Destacamos que os mais recorrentes são a relação deficitária entre teoria e prática na licenciatura, ou seja, as disciplinas que se propõem a serem sobre prática de ensino acabam por trazer mais teorizações desvinculadas das ações nas escolas; a falta de diálogo entre os saberes pedagógicos e do conhecimento; ausência de perspectivas teórico-metodológicas que dialoguem com a Didática da História, o que podemos elencar com a problemática anterior, na qual não há relação entre a formação sobre o ensino aliados à aprendizagem da ciência histórica a partir da História como referência; a desvalorização da licenciatura (docência/ensino) frente ao bacharelado (pesquisa), o que acaba por reforçar a dualidade docência versus pesquisa; disciplinas que se encontram sob a tutela dos departamentos e faculdades de educação, mas que não tem qualquer relação ou diálogo com os docentes e disciplinas da área da história; e pouca experiência docente nas práticas de ensino nas disciplinas que, supostamente, seriam sobre prática de ensino.

Percebamos, portanto, que a desarticulação entre saberes do conhecimento e saberes pedagógicos bastante debatida, pesquisada e apontada como uma das principais dificuldades formativas sentidos pelos discentes dos cursos de História curricularmente. 
É consenso entre os trabalhos analisados a respeito do currículo e da formação de professores de História a necessidade de integração dos colegiados responsáveis por formar os professores, necessidade de articulação teoria e prática, superação da divisão bacharelado/pesquisa e licenciatura/ensino e articulação entre os saberes pedagógicos e do conhecimento.

\section{Referências}

AZEVEDO, Fernando de, et al. O Manifesto dos Pioneiros da Educação Nova (1932). Revista HISTEDBR On-line, Campinas, n. especial, p.188-204, ago. 2006. Disponível em: https://fe-old.fe.unicamp.br/pffe/publicacao/4921/doc1_22e.pdf. Acesso em: 24/04/2018.

BARDIN, Laurence. Análise de conteúdo. Lisboa: Edições 70, 1977.

FERREIRA, Marieta de Moraes. O ensino da história na Faculdade Nacional de Filosofia da Universidade do Brasil. História, Ciências, Saúde-Manguinhos, Rio de Janeiro, RJ, v. 19, n. 2, abr.-jun. 2012, p. 611-636. Disponível em: http://www.scielo.br/pdf/hcsm/v19n2/14.pdf. Acesso em: 26/10/2017.

FERREIRA, Norma Sandra de Almeida. As pesquisas denominadas "estado da arte". Educação \& Sociedade, São Paulo, SP, ano 23, n. 79, p. 257-272, ago. 2002. Disponível em: http://www.scielo.br/pdf/es/v23n79/10857.pdf. Acesso em: $13 / 11 / 2017$.

FONSECA, Selva Guimarães. Caminhos da História ensinada. 13. ed. Campinas: Papirus, 2011.

FREITAS, Itamar. Reformas educacionais e os currículos nacionais para o ensino de história no Brasil republicano (1931/2009). Cadernos de História da Educação, Uberlândia, MG, v. 12, n. 1, p. 187-202, jan./jun. 2013. Disponível em: http://www.seer.ufu.br/index.php/che/article/view/22903/12430. Acesso em: $21 / 05 / 2018$

MESQUITA, Ilka Miglio de; FONSECA, Selva Guimarães. Formação de professores de História: experiências, olhares e possibilidades. História Unisinos, São Leopoldo, RS, v. 10, n. 3, p. 333-343, set./dez. 2006. Disponível em: http://revistas.unisinos.br/index.php/historia/article/view/6187. Acesso em: 06/02/2018.

NASCIMENTO, Thiago Rodrigues. A formação do professor de História no Brasil: percurso histórico e periodização. História Hoje: Revista de História e Ensino, São Paulo, SP, v. 2, n. 4, p. 265-304, 2013. Disponível em: https://rhhj.anpuh.org/RHHJ/article/view/98/79. Acesso em: 08/05/2018. 
PACIEVITCH, Caroline. Conhecimento didático e formação de professores de história: contribuições para a teoria e a prática. Diálogo Andino: Revista de História, Geografia y Cultura Andina, Arica, n. 52, p. 117-126, 2017. Disponível em: https://www.scielo.cl/pdf/rda/n53/0719-2681-rda-53-00117.pdf. Acesso em: $23 / 04 / 2018$.

PIMENTA, Selma Garrido; LIMA, Maria Socorro Lucena. Estágio e docência. 3. ed. São Paulo: Editora Cortez, 2008.

RAYS, Oswaldo Alonso. A relação teoria-prática na didática escolar crítica. In: VEIGA, Ilma Passos Alencastro (org.). Didática: o ensino e suas relações. Campinas, SP: Papirus Editora, 1996. p. 33-52.

RICCI, Cláudia Sapag. Historiador e/ou professor de História: a formação nos cursos de graduação de História. História Hoje: Revista de História e Ensino, São Paulo, v. 4, n 7, p. 107-135, 2015. Disponível em: https://rhhj.anpuh.org/RHHJ/article/view/178/127. Acesso em: 23/04/2018.

RODRIGUES, Mara Cristina de Matos. A formação superior em história na UPA/URGS/UFRGS de 1943-1971. História da Historiografia, Mariana, n. 11, p. 122-139, abr. 2013. Disponível em: https://www.historiadahistoriografia.com.br/revista/article/view/544. Acesso em: 24/05/2018.

ROIZ, Diogo Silva. A institucionalização do ensino universitário de Geografia e História na faculdade de filosofia, Ciências e Letras da Universidade de São Paulo entre 1934 e 1956. Ágora: Revista do Departamento de História e Geografia, Santa Cruz do Sul, v. 13, n. 1, p. 65-104, jan./jun. 2007. Disponível em: https://online.unisc.br/seer/index.php/agora/article/view/111. Acesso em: 21/05/2018.

SCHMIDT, Maria Auxiliadora Moreira dos Santos. História do ensino de história no Brasil: uma proposta de periodização. Revista História da Educação - RHE, Pelotas, v. 16, n. 37, p. 73-91, maio/ago. 2012. Disponível em: https://seer.ufrgs.br/index.php/asphe/article/view/24245. Acesso em: 21/05/2018.

SILVA, Norma Lúcia da; FERREIRA, Marieta de Moraes. Os caminhos da institucionalização do ensino superior de história. História \& Ensino, Londrina, v. 17, n. 2, p. 283-306, jul./dez. 2011. Disponível em: http://www.uel.br/revistas/uel/index.php/histensino/article/view/11242. Acesso em: 10/05/2017. 